\title{
Gastroenteritis attributable to rotavirus in hospitalized Saudi Arabian children in the period 2007-2008
}

This article was published in the following Dove Press journal:

Clinical Epidemiology

II February 2015

Number of times this article has been viewed

\author{
Mohamed Khalil' \\ Esam Azhar ${ }^{2,3}$ \\ Moujahed $\mathrm{Kao}^{3}$ \\ Noura Al-Kaiedi ${ }^{3}$ \\ Hatim Alhani ${ }^{4}$ \\ Ibrahim Al Olayan ${ }^{5}$ \\ Robert Pawinski6,7 \\ Kusuma Gopala ${ }^{8}$ \\ Walid Kandeil ${ }^{7}$ \\ Sameh Anis ${ }^{7,9}$ \\ Leen Jan Van Doorn ${ }^{10}$ \\ Rodrigo DeAntonio ${ }^{7}$ \\ 'Public Health and Research \\ Development, Ministry of Health, \\ Riyadh, Saudi Arabia; ${ }^{2}$ Medical \\ Laboratory Technology Department, \\ Faculty of Applied Medical Sciences, \\ ${ }^{3}$ Special Infectious Agents Unit, \\ Bio-Safety Level 3, King Fahad \\ Medical Research Center, King \\ Abdulaziz University, Jeddah, Saudi \\ Arabia; ${ }^{4}$ Maternity and Children's \\ Hospital, Dammam, Saudi Arabia; \\ ${ }^{5}$ Maternity and Children's Hospital, \\ Qassim, Saudi Arabia; 'Reckitt \\ Benckiser Pharmaceuticals, Slough, \\ UK; ${ }^{7}$ GlaxoSmithKline Vaccines, \\ Wavre, Belgium; ${ }^{8} \mathrm{GlaxoSmithKline}$ \\ Pharmaceuticals Ltd, Bangalore, \\ Karnataka, India; ${ }^{9} \mathrm{AbbVie}$ \\ Biopharmaceuticals GmbH, Dubai, \\ United Arab Emirates; ${ }^{10} \mathrm{DDL}$ \\ Diagnostic Laboratory, Rijswijk, \\ the Netherlands
}

Correspondence: Mohamed Khali Public Health and Research Development, Ministry of Health, PO Box 88300,

Riyadh II 662, Saudi Arabia

Tel +96654955087

Email statkhl@hotmail.com
Purpose: Rotavirus (RV) is a leading cause of severe gastroenteritis (GE) in children across the world. As there is a lack of epidemiological data for RV gastroenteritis (RVGE) in Saudi Arabia, this hospital-based study was designed to estimate the disease burden of RVGE and assess the prevalent RV types in Saudi children younger than 5 years of age.

Patients and methods: Children hospitalized for acute GE were enrolled at four pediatric referral hospitals in Saudi Arabia. The study was conducted from February 2007 to March 2008 and used the World Health Organization's generic protocol for RVGE surveillance. The Vesikari severity scale was used to assess the severity of RVGE. Stool samples were tested for RV using an enzyme-linked immunosorbent assay. Samples were further typed by reverse transcriptasepolymerase chain reaction and hybridization assay for determining the $\mathrm{G}$ and $\mathrm{P}$ types.

Results: A total of 1,007 children were enrolled; the final analysis included 970 children, of whom 395 were RV positive, 568 were RV negative, and seven had unknown RV status. The proportion of RVGE among GE hospitalizations was 40.7\% (95\% confidence interval: 37.6-43.9). The highest percentage of RVGE hospitalizations (83.1\%) was seen in children younger than 2 years of age. The highest proportion of RV among GE hospitalizations was in June 2007 with $57.1 \%$. The most common RV types detected were G1P[8] (49.3\%), G1G9P[8] (13.2\%), and G9P[8] (9.6\%). Before hospitalization, severe GE episodes occurred in $88.1 \%$ RV-positive and $79.6 \%$ RV-negative children. Overall, 94\% children had recovered by the time they were discharged. Two children (one RV positive and one RV negative) died due to GE complications.

Conclusion: RVGE is responsible for a high proportion of hospitalizations in Saudi children younger than 5 years of age. Routine RV vaccination has therefore been introduced into the national immunization program and may help reduce the morbidity, mortality, and disease burden associated with RVGE in Saudi Arabia.

Keywords: disease burden, Saudi Arabia, rotavirus, RVGE, epidemiology

\section{Introduction}

Globally, rotavirus (RV) is the most common etiological agent for acute gastroenteritis (GE), ${ }^{1}$ accounting for around 453,000 annual global deaths ${ }^{2}$ and over two million hospitalizations among children younger than 5 years of age. ${ }^{3}$ Data from the coordinated global network for rotavirus surveillance of the World Health Organization (WHO) at 185 sentinel sites in 64 countries showed RV detection rates of $37 \%-53 \%$ in children hospitalized with diarrhea in 2011 in regions of the world where vaccination has not been widely implemented ${ }^{2}$ and $\mathrm{RV}$ is one of the most common causes of moderate to severe diarrhea during the first 2 years of life. ${ }^{4}$ Most deaths due to RV occur in developing countries where there is underlying malnutrition and a lack of timely access to health care facilities. 5 
Saudi Arabia is a developing country with a population of 28 million, where children younger than 5 years of age represent approximately $9 \%$ of the population. There are 614,000 live births annually. ${ }^{6}$ Previous studies on RV gastroenteritis (RVGE) in the Arabic peninsula have shown that RV is the causative agent in $21 \%-40 \%$ of cases of infantile GE. ${ }^{7-9}$ In Saudi Arabia, studies indicate RVGE to be responsible for $16 \%-46 \%$ of infections in infants and children. ${ }^{10-13}$ There is a higher disease burden in children younger than 2 years of age, with more than $87 \%$ of RVGE affecting children younger than 2 years of age; moreover, it is also seen to vary across seasons. ${ }^{11,14,15}$ However, to date, no national studies have been conducted. Recent studies in the country have indicated that RVGE remains the most common cause of infectious diarrhea in young children, ${ }^{16,17}$ but the prevalence of RV may have decreased. ${ }^{18,19}$ Although effective control of RVGE relies upon knowledge of national disease burden data and the prevalent circulating strains of RV, more data need to be collected for Saudi Arabia.

Interventions such as increased sanitation and antimicrobial treatments that have decreased diarrhea associated with bacterial and parasitic agents are less effective against $\mathrm{RV}$, which spreads from person to person and currently has no specific treatment. ${ }^{2}$ However, two live, oral RV vaccines, Rotarix $^{\circledR}$ (GSK Vaccines, Belgium) and RotaTeq ${ }^{\circledR}$ (Merck \& Company Inc., West Point, PA, USA) have demonstrated good safety and efficacy in large-scale clinical trials and case-control studies, as well as in postvaccination effectiveness studies in different regions of the world. ${ }^{4,20-23}$ Consequently, in 2009, the WHO recommended the inclusion of RV vaccines into the national immunization programs of all countries. ${ }^{24-26}$ In January 2013, Saudi Arabia introduced RV vaccine into the national immunization program. ${ }^{6}$

This hospital-based surveillance study, conducted prior to the introduction of the vaccine, was designed to estimate the proportion of acute GE hospitalizations in Saudi children younger than 5 years of age that could be attributed to RV. The study evaluated age distribution patterns, seasonality of RVGE and acute GE hospitalizations, prevalent RV strains, GE episode severity, and the outcome and treatments associated with RVGE.

\section{Materials and methods Study design}

This multicenter, hospital-based, observational, crosssectional study was conducted in accordance with the WHO generic protocol for hospital-based surveillance to estimate the burden of RVGE among children, ${ }^{27}$ and in accordance with it, this prospective surveillance study was conducted in four pediatric referral hospitals. Each hospital selected for surveillance had the laboratory capacity to perform RV detection using rapid antigen detection methods or a reliable system for transporting specimens to a reference laboratory. This capability included the resources necessary for collecting stools appropriately and in a timely fashion, the storage of specimens in a refrigerator or freezer until testing is performed, personnel trained in testing methods, and adequate record-keeping practices to allow the coordination of laboratory and clinical data. The study was conducted in hospitals in the major cities of Dammam (eastern region), Makkah (western region), Jizan (southern region), and Qassim (central region) in the period between February 2007 and March 2008. It included all children $<5$ years of age hospitalized for GE in that period. A questionnaire was circulated to solicit information about demographics (age, sex, height, and weight), medical history, GE symptoms, treatment prior to hospitalization, and area of residence. A stool sample was collected from all enrolled children. These stool samples were tested for the presence of $\mathrm{RV}$, a subset of which was serotyped. The severity of RVGE was assessed using the Vesikari scale.

\section{Study population and case definition}

Children younger than 5 years of age who were hospitalized for acute GE were eligible for enrollment in the study. A case of acute GE was defined according to the following WHO definition: "three or more loose stools and/or two or more vomiting episodes within a 24-hour period, with the onset of symptoms $\leq 14$ days before admission". ${ }^{27}$ Children were excluded if they did not meet the case definition of acute GE, visited the emergency room or the outpatient department for treatment, or developed GE 12 hours after admission to the hospital (possible nosocomial infections). Each hospitalization was considered a new and separate case.

\section{Data collection}

Parents/guardians completed a questionnaire to provide information about demographics (age, sex, height, and weight), medical history, GE symptoms, treatment prior to hospitalization, and area of residence. Clinical severity and symptoms were obtained by reviewing the medical records. A 20-point Vesikari scale was used to assess the severity of RVGE (severe RVGE $=$ Vesikari score $\geq 11) .{ }^{28}$

\section{Laboratory analyses}

Stool samples were collected from all enrolled children, divided into two aliquots, and stored in the refrigerator at a 
temperature between $2^{\circ} \mathrm{C}$ and $8^{\circ} \mathrm{C}$ for up to 24 hours and later at $-20^{\circ} \mathrm{C}$. One set of samples was tested at a single laboratory using the IDEIATM (Dako, Ely, UK) RV test for the detection of RV (Group A) using an enzyme-linked immunosorbent assay. A subset of 122 RV-positive and 14 RV-negative samples were randomly selected and sent to DDL Diagnostic Laboratory, the Netherlands, for further typing to detect $\mathrm{G}$ and $P$ types using standardized reverse transcriptase-polymerase chain reaction and hybridization assay. ${ }^{29}$

\section{Statistical analyses}

The analysis was performed for all subjects who met the eligibility criteria and agreed to participate. Summary statistics for demographic characteristics and percentages for categorical data were computed. The target enrollment was approximately 1,500 children with acute GE, based on the assumption that $20 \%-40 \%$ of these children would be RV positive..$^{30}$

The analytical plan was modified to get a clearer picture of the disease burden, with a focus on the proportion of diarrheal hospitalizations attributable to RVGE in children $<5$ years of age. Incidence could not be calculated due to the nonavailability of population data. To calculate this proportion, the number of children with RVGE was divided by the number of children with acute GE and the result was multiplied by 100 (to express as percentage).

Chi-square and Fisher's exact tests were performed as post hoc, exploratory analyses to compare symptoms and test the differences in proportions between RV-positive and RV-negative subjects. All statistical analyses were descriptive and performed using SAS version 9.2 (SAS Institute Inc., Cary, NC, USA). The $95 \%$ exact confidence intervals were calculated using ProcStatXact.

\section{Ethical considerations}

This study was conducted in accordance with Good Clinical Practice guidelines and the Declaration of Helsinki IV (1996) and was approved by the National Ethics Committee at the Ministry of Health. Parents/guardians provided written informed consent before the start of the study.

\section{Results \\ Baseline characteristics}

A total of 1,007 children were finally enrolled, of whom 970 were included in the final analyses. Thirty-seven children were not included due to the following reasons: the date of stool sample collection was outside the interval of $>4$ days and $<10$ days after GE onset $(n=20)$; no information on informed consent $(\mathrm{n}=8)$; no information on admission and general symptoms $(n=1)$; not meeting the eligibility criteria (most were children who did not meet the case definition of acute GE; $n=8)$. The baseline characteristics are detailed in Table 1.

\section{Clinical characteristics}

The signs and symptoms demonstrated by children admitted with acute GE are summarized overall and by RV status. Before hospitalization, 88.1\% (348/395) RV-positive children and 79.6\% (452/568) RV-negative children recorded severe GE, as assessed by the Vesikari scale. Exploratory analysis showed that this association between RV status and GE severity was statistically significant $(P=0.0005)$. During hospitalization, 25.8\% (102/395) RV-positive children and 23.4\% (133/568) RV-negative children recorded severe GE.

Inpatient treatment consisted primarily of intravenous rehydration, which was administered to $98.0 \%$ (387/395) RV-positive children and 97.5\% (554/568) RV-negative children (Table 2). The mean duration of hospitalization was $4.0( \pm 1.8)$ days for RV-positive children and $4.3( \pm 2.1)$ days for RV-negative children. Overall, $94 \%$ of children had recovered by the time they were discharged from hospital, but two children (one RV positive and one RV negative) died due to GE complications.

\section{Proportions of acute GE and RVGE hospitalizations}

A total of 395 children tested positive for RV, 568 were RV negative, and seven had unknown RV status because their stool samples were not collected.

Table I Summary of baseline characteristics $(\mathrm{N}=970)$

\begin{tabular}{|c|c|c|c|}
\hline Characteristics & $\begin{array}{l}\text { RV-positive } \\
\text { patients } \\
(\mathbf{N}=395)\end{array}$ & $\begin{array}{l}\text { RV-negative } \\
\text { patients } \\
(\mathbf{N}=568)\end{array}$ & $P$-values \\
\hline \multicolumn{4}{|l|}{ Age (in months) } \\
\hline $\mathrm{n}$ (mean) & $395(8.3)$ & $568(10.7)$ & 0.75 \\
\hline Minimum & 0 & 0 & \\
\hline Maximum & 48 & 48 & \\
\hline \multicolumn{4}{|l|}{ Sex (\%) } \\
\hline Female & $165(41.8)$ & $253(44.5)$ & 0.39 \\
\hline Male & $230(58.2)$ & $315(55.5)$ & \\
\hline \multicolumn{4}{|l|}{ Living in area (\%) } \\
\hline No & $5(1.3)$ & $9(1.6)$ & 0.68 \\
\hline Yes & 390 (98.7) & 559 (98.4) & \\
\hline
\end{tabular}

Notes: $\mathrm{N}$, number of subjects; $\mathrm{n}$, number of subjects in a given category; $\%=n /$ number of subjects with available results $\times 100$. Seven subjects had an unknown $\mathrm{RV}$ status because sample was not collected.

Abbreviation: RV, rotavirus. 
Table 2 Clinical characteristics of all children hospitalized for acute GE

\begin{tabular}{|c|c|c|c|}
\hline \multirow[t]{2}{*}{ Signs and symptoms } & \multicolumn{3}{|c|}{ n (\% of children) } \\
\hline & $\begin{array}{l}\text { RV positive } \\
(\mathrm{N}=395)\end{array}$ & $\begin{array}{l}\text { RV negative } \\
(\mathrm{N}=568)\end{array}$ & $\begin{array}{l}\text { Overall } \\
(\mathrm{N}=970)\end{array}$ \\
\hline \multicolumn{4}{|c|}{ Severity before hospitalization } \\
\hline Mild (I-6) & $3(0.8)$ & $4(0.7)$ & $8(0.8)$ \\
\hline Moderate $(7-10)$ & $44(11.1)$ & $112(19.7)$ & $157(16.2)$ \\
\hline Severe $(\geq I I)$ & $348(88.1)^{*}$ & $452(79.6)^{*}$ & $805(83.0)$ \\
\hline \multicolumn{4}{|c|}{ Symptoms before hospitalization } \\
\hline Diarrhea & $395(100)$ & $567(99.8)$ & $968(99.8)$ \\
\hline Vomiting & $368(93.2)$ & $485(85.4)$ & $859(88.6)$ \\
\hline Fever & $292(73.9)$ & $436(76.8)$ & $732(75.5)$ \\
\hline \multicolumn{4}{|c|}{ Degree of dehydration before hospitalization } \\
\hline Mild/moderate (I\%-5\%) & $265(67.1)$ & $333(58.9)$ & $604(62.5)$ \\
\hline Severe $(\geq 6 \%)$ & $71(18.0)$ & $62(11.0)$ & $134(13.9)$ \\
\hline \multicolumn{4}{|c|}{ Number of days of diarrhea before hospitalization } \\
\hline $1-4$ & $337(85.3)$ & $463(81.7)$ & $806(83.3)$ \\
\hline 5 & $25(6.3)$ & $42(7.4)$ & $67(6.9)$ \\
\hline$\geq 6$ & $33(8.4)$ & $62(10.9)$ & $95(9.8)$ \\
\hline \multicolumn{4}{|l|}{ Duration of hospitalization } \\
\hline Mean $( \pm S D)$, days & $4.0(1.78)$ & $4.34(2.13)$ & $4.20(2.03)$ \\
\hline \multicolumn{4}{|c|}{ Treatment received during hospitalization } \\
\hline Oral rehydration & $247(62.5)$ & $354(62.3)$ & $605(62.4)$ \\
\hline IV rehydration & $387(98.0)$ & $554(97.5)$ & $946(97.6)$ \\
\hline Antibiotics & $164(4 \mid .5)$ & $328(57.7)$ & $494(51.0)$ \\
\hline \multicolumn{4}{|l|}{ Outcome at discharge } \\
\hline Recovered & $370(93.7)$ & $537(94.5)$ & $912(94.0)$ \\
\hline $\begin{array}{l}\text { Recovered } \\
\text { with sequelae }\end{array}$ & $0(0.0)$ & $3(0.5)$ & $3(0.3)$ \\
\hline Ongoing & $22(5.6)$ & $26(4.6)$ & $48(4.9)$ \\
\hline $\begin{array}{l}\text { Transferred to } \\
\text { another hospital }\end{array}$ & $0(0.0)$ & $\mathrm{I}(0.2)$ & $2(0.2)$ \\
\hline Died & $\mathrm{I}(0.3)$ & $\mathrm{I}(0.2)$ & $2(0.2)$ \\
\hline Unknown & $2(0.5)$ & $0(0.0)$ & $3(0.3)$ \\
\hline
\end{tabular}

Note: $* P=0.0005$ ( $\chi^{2}$ test for association between severity and GE status). Abbreviations: GE, gastroenteritis; RV, rotavirus; SD, standard deviation; $\mathrm{IV}$, intravenous; $\mathrm{N}$, number of subjects; $\mathrm{n}$, number of subjects in a given category.

The overall proportion of RVGE among all children hospitalized for acute GE and tested for RV was $40.7 \%$ (95\% confidence interval: 37.6-43.9). The largest numbers of hospitalizations for acute GE $(39.2 \%$; 380/970) were recorded at the Maternity and Children's Hospital, Dammam, and the RVGE-attributable fraction was 43.9\% (167/380). The RVGEattributable fractions in Makkah, Jizan, and Qassim were 39.7\% (64/161), 43.1\% (84/195), and 34.2\% (80/234), respectively.

In children aged between 0 month and 11 months, $41.6 \%$ (217/521) were positive for RVGE; 41.6\% (111/242) of children between the ages of 12 months and 23 months were positive for RVGE, and in children older than 24 months, $33.5 \%$ (67/200) were RVGE positive (Figure 1). A statistically significant association $(P=0.029)$ was found between the $\mathrm{RV}$ status and the different age groups ( 0 month -11 months, 12 months -23 months, and $\geq 24$ months).

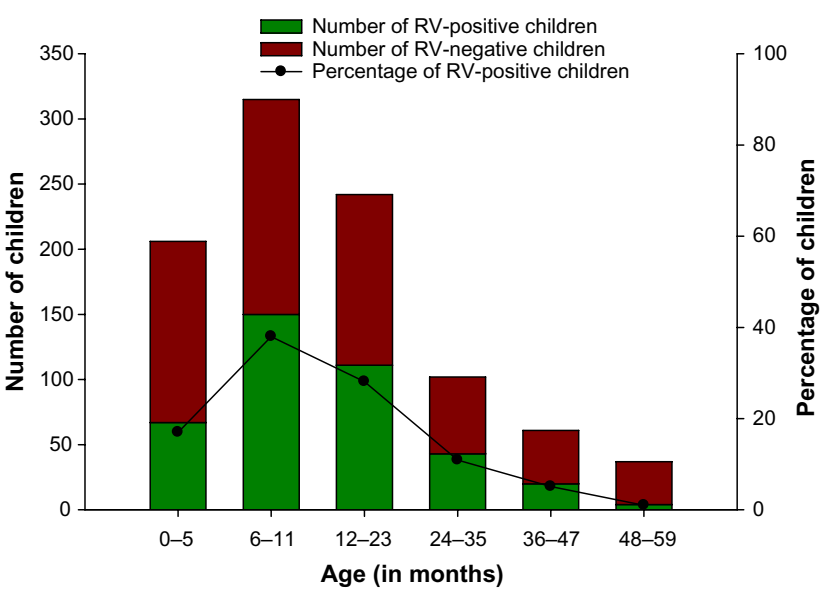

Figure I Proportion of acute GE hospitalizations attributable to RV ( $N=970)$. Abbreviations: GE, gastroenteritis; RV, rotavirus.

\section{Seasonal distribution}

The highest number of acute GE hospitalizations (127 cases) was reported in July 2007. Although RVGE occurred throughout the year, the highest proportion of RV among GE patients occurred in June 2007 (57.14\%, 44/77), followed by August 2007 (52.0\%, 52/100), and February 2008 $(51.5 \%, 38 / 68)$ (Figure 2). August 2007, July 2007, and June 2007 had the largest number of RVGE cases with 54, 52 , and 44 cases, respectively.

\section{RV type distribution}

A total of 136 stool samples were randomly assessed for $\mathrm{G}$ and $\mathrm{P}$ types of RV in the DDL laboratory (122 RV positive and 14 RV negative). Moreover, G1 (53.7\%; 73/136) and P[8] $(75 \% ; 102 / 136)$ were the most prevalent types, followed by $\mathrm{G} 1+\mathrm{G} 9(14.7 \%)$ and $\mathrm{P}[4]+\mathrm{P}[8](2.9 \%)$ (Figure 3).

G1P $[8](49.3 \%$; 67/136) was the predominant combination type, followed by G1+G9P[8] $(13.2 \% ; 18 / 136)$ and G9P[8] (9.6\%; 13/136) (Figure 4).

\section{Discussion}

Our hospital-based surveillance provides data on morbidity and hospitalization due to RVGE in four pediatric referral hospitals across Saudi Arabia. This is the most recent baseline, prevaccination data and the first at the national level for the epidemiology of RV in the Saudi Kingdom. Over 1,000 children hospitalized with acute GE were enrolled and tested for RV from February 2007 through March 2008.

During the 12-month enrollment period for children $<5$ years of age, the total birth cohort was evaluated to be 28,381 (10,000 in Qassim, 8,280 in Damman, 7,734 in Makkah, and 2,367 in Jizan); the total number of GE-related 


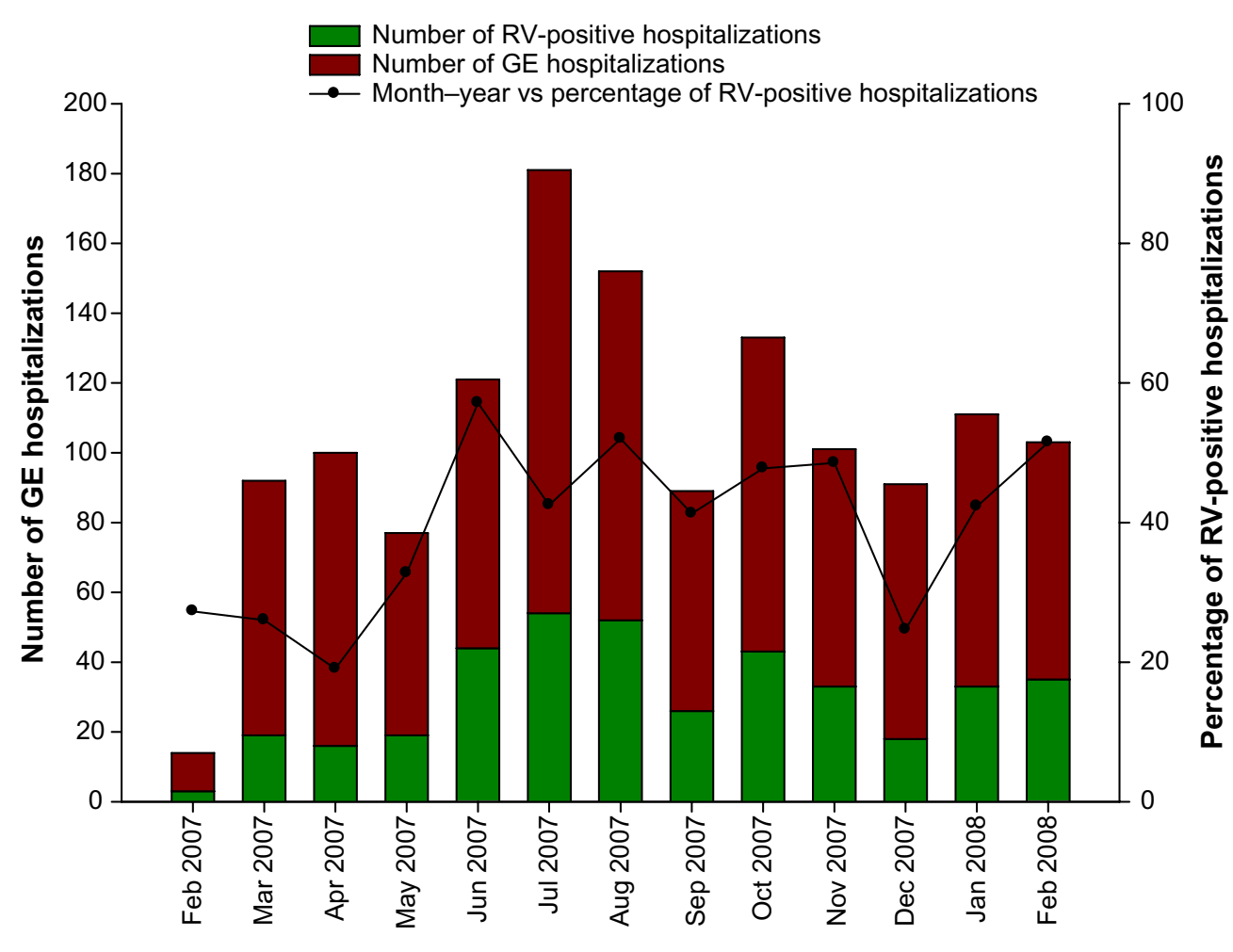

Months

Figure 2 Seasonal distribution of RVGE and GE hospitalizations ( $N=970)$.

Note: The X-axis represents the months February 2007 through February 2008.

Abbreviations: GE, gastroenteritis; RV, rotavirus; RVGE, RV gastroenteritis.

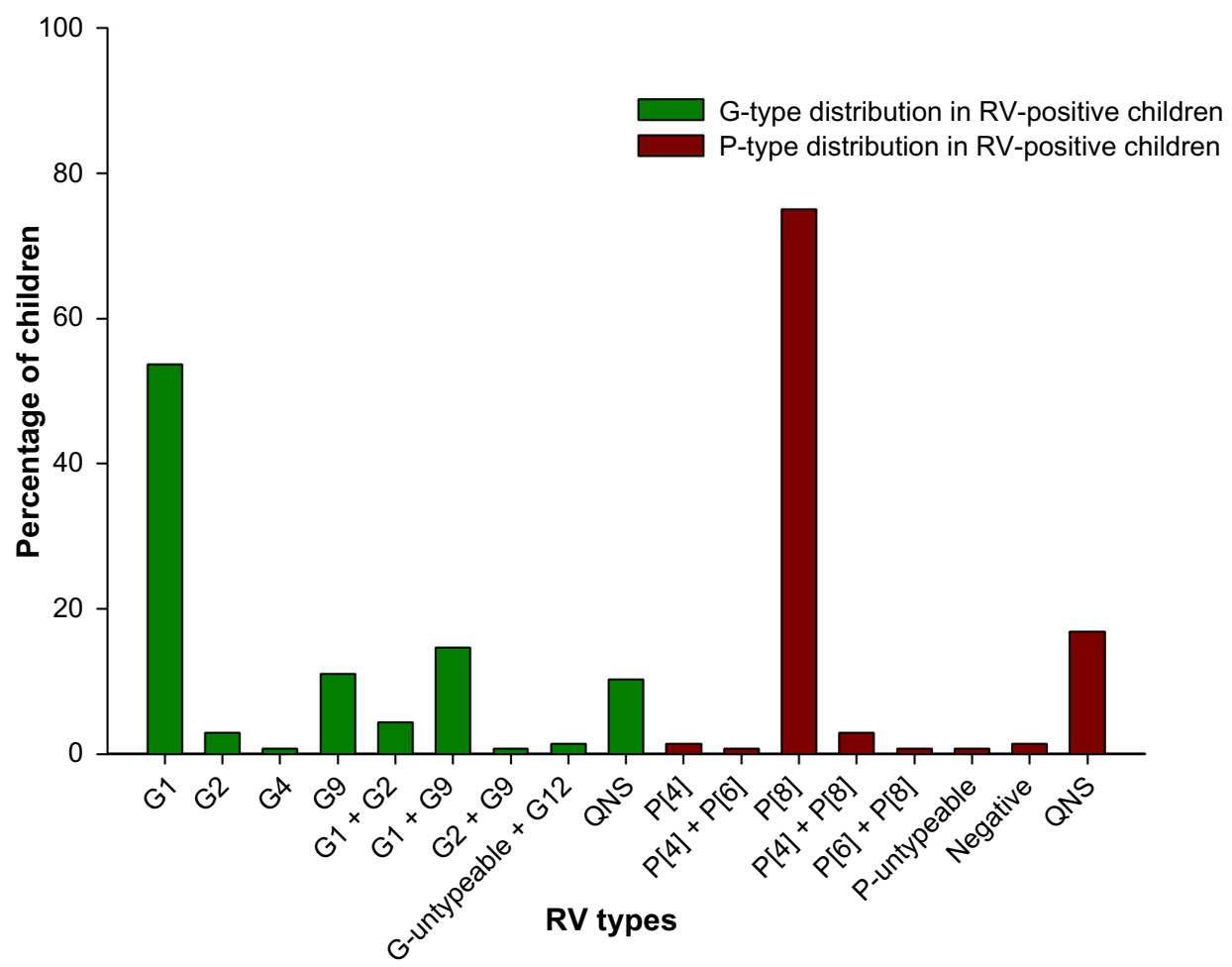

Figure 3 Distribution of RV G and $P$ types $(\mathrm{N}=136)$.

Abbreviations: QNS, quantity not sufficient; RV, rotavirus. 


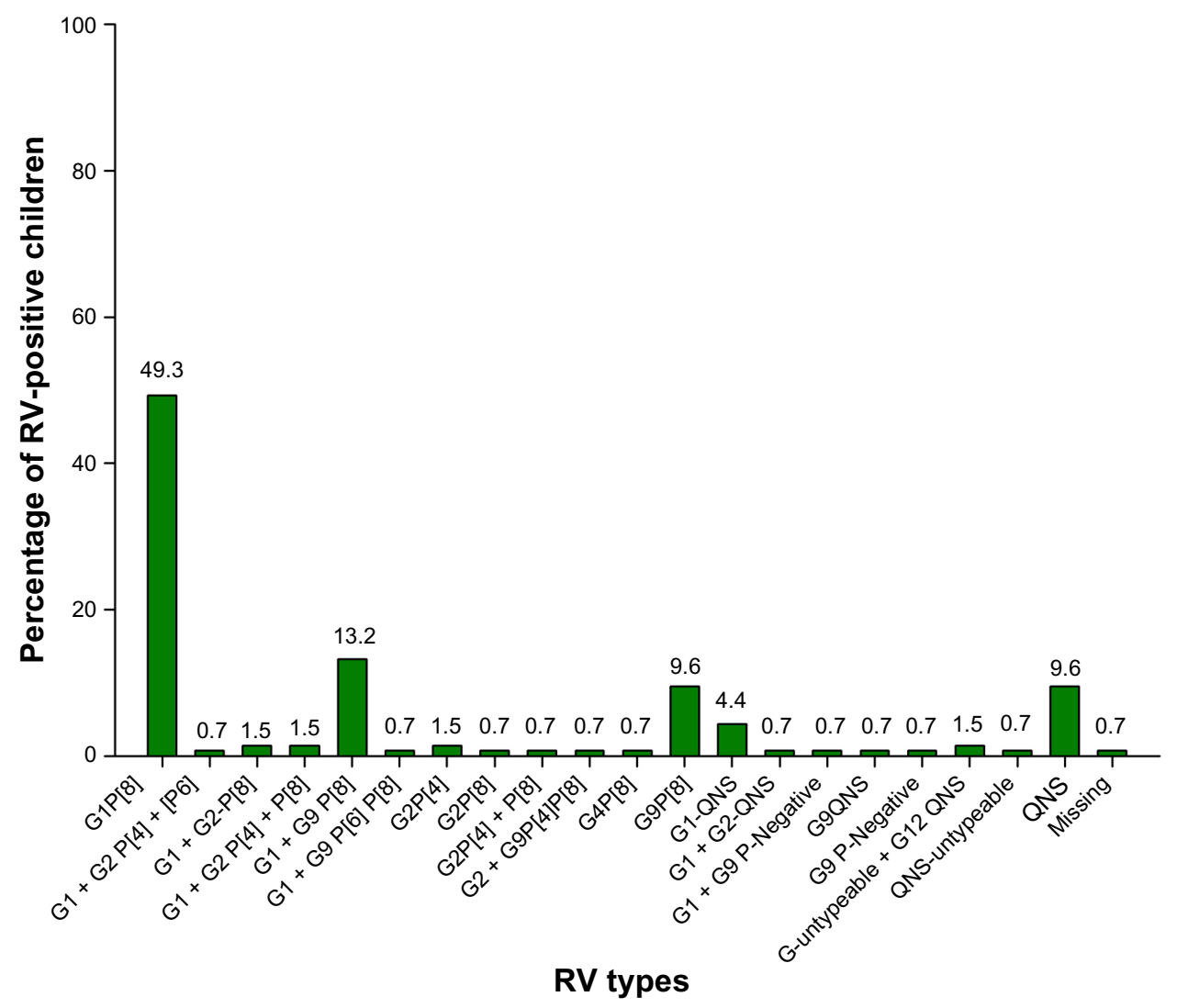

Figure 4 Distribution of RV combination types among RV-positive children $(\mathrm{N}=136)$. Abbreviations: QNS, quantity not sufficient; RV, rotavirus.

admissions of children $<5$ years old at these study sites per year was 1,448 (300 in Qassim, 607 in Damman, 350 in Makkah, and 191 in Jizan). On the basis of this evaluation, 141,905 subject-years were to be followed, leading to 1,447 GE admissions.

We found that RV is a major cause of acute GE, accounting for $40.7 \%$ of GE-related hospitalizations in children $<5$ years of age. These study results are consistent with the 16\%-61\% RVGE reported from the Eastern Mediterranean region ${ }^{31}$ and a median of $36 \%$ estimated from global studies..$^{32} \mathrm{~A}$ review of 22 published studies indicates that RVGE prevalence varies across Saudi Arabia: median values range from $16 \%$ for Jizan located in the southern region, $23 \%$ for Riyadh in the central region, $24.5 \%$ for Damman in the eastern region, and $42.4 \%$ for Al-taif and Jeddah in the western region. ${ }^{16}$

As found in different studies from the Eastern Mediterranean region, RVGE disease burden in our study was highest in children $<2$ years of age. ${ }^{18,31,33,34}$ Furthermore, GE severity was closely associated with RV infection, as has been previously described..$^{35}$ As expected, almost all hospitalized children required intravenous rehydration therapy.
In this study, RV persisted throughout the year with no obvious peaks, which is consistent with earlier reports from Saudi Arabia ${ }^{36,37}$ and other Middle Eastern countries. ${ }^{33,38,39}$ However, another study conducted in Saudi Arabia between 2004 and 2005 reported a peak during the cooler months of November and December, with lowest infection rates in June, ${ }^{40}$ whereas another study conducted in Bahrain between 2006 and 2007 reported RVGE peaks in April ${ }^{41}$ this might indicate differences in circulation from one year to the other.

Strain prevalence data from our study showed that G1P[8] was the most commonly detected RV combination type, accounting for over half of all RV strains, followed by G1 + G9P[8] and G9P[8]. These data are consistent with published results for the region, which show that G1P[8] is also the most commonly detected RV type in Turkey ${ }^{39}$ and other Middle Eastern countries. ${ }^{19}$ However, in Iran, G4P[8] is the most common RV type ${ }^{33}$ and in Oman, a more diverse strain pattern has been noted. ${ }^{42}$ This may be attributed to the seasonal variation in circulating strains. Seasonal variation suggests that vaccines that have cross-protection and wide coverage are more effective and also highlights that 
continuous monitoring for new emergent strains of RV is a priority.

The results of our study need to be interpreted in the context of some limitations. We initially planned to compute RVGE incidence data in Saudi children, but this could not be calculated due to uncertainty about the exact size of the population in the catchment areas. Our study was also designed to assess only hospitalized cases of acute GE in urban cities; therefore, data from children who were managed at home, in the emergency rooms, or as outpatients were not collected. However, this covered a significant proportion of the national birth cohort. The extents to which the rates of RVGE differ (with respect to incidence in the community and presenting to general practice) have been previously studied in the UK. ${ }^{43,44}$ All of this could lead to underestimation of RVGE occurrence. In this study, we concentrated on hospitalized cases, as they represent more severe cases and directly affect the medical and economic resources of the country.

Additionally, because data were collected for only 1 year, it is difficult to draw conclusions about the seasonality of RVGE, and this indicates the need for continuous monitoring. Another important limitation of the study was that despite using the more sensitive enzyme-linked immunosorbent assay test vs the latex agglutination test, ${ }^{45}$ there were some false-negative samples, as confirmed by DDL testing, but there were no false positives noted. Despite these limitations, the main strengths of our study were in undertaking systemic surveillance using WHO indications ${ }^{27}$ (comprising well-established case definitions and standard data collection) and in using a validated laboratory for strain identification and RV G and P typing. Our study was conducted in four large pediatric referral hospitals across the country, with no major differences seen between hospitals, suggesting that our findings are likely to be representative of a large portion of the population.

Data from this hospital-based surveillance emphasize that RV is an important cause of acute GE hospitalization in young Saudi children and therefore suggests that preventive steps are necessary. As there is currently no available antiviral therapy, the acute dehydration caused by RVGE is routinely managed by fluid and electrolyte replacement. ${ }^{45}$ Vaccination is a recommended and effective public health intervention against RV and there are data from real-world settings demonstrating a substantial public health impact of RV vaccination in reducing disease burden. ${ }^{23,46}$ Countries from around the world ${ }^{47,48}$ and from the Middle Eastern Region ${ }^{48}$ have recently introduced RV vaccination into their national immunization plans (including Bahrain in 2008, Qatar in 2009, and Iraq and Yemen in 2012). ${ }^{49}$
The Saudi health care system is relatively advanced under the guidance of the Ministry of Health ${ }^{50}$ and in January 2013, Saudi Arabia introduced RV vaccine into the National Immunization Program. ${ }^{6}$ Data from the current study provide a useful prevaccination baseline. Future studies/surveillance will now be required to monitor the circulating strains and to record the impact of vaccination. Monitoring will also help to determine the emergence of new genotypes and give further insight into the optimization of strategies for effective RV prevention.

\section{Conclusion}

Our national study showed attributable fraction of $40.7 \%$ for RVGE among cases of acute GE hospitalizations between 2007 and 2008 in children $<5$ years of age in Saudi Arabia. These data support the continual inclusion of RV vaccine into the national immunization schedule to reduce the burden of RVGE in Saudi Arabia.

\section{Acknowledgments}

The authors would like to thank the DDL Diagnostic Laboratory, the Netherlands, for performing the genotyping assay. The authors also thank Shruti Priya Bapna and Preethi Govindarajan (employed by GlaxoSmithKline group of companies) for preparing the manuscript, Abdelilah Ibrahimi (XPE Pharma and Science on behalf of GlaxoSmithKline Vaccines) for publication coordination, and Julia Donnelly (on behalf of GlaxoSmithKline Vaccines) for support in English editing.

GlaxoSmithKline Biologicals SA funded this study and was involved in all stages of study conduct, including analysis of the data. GlaxoSmithKline Biologicals SA also took charge of all costs associated with the development and publication of this manuscript.

\section{Author contributions}

Mohamed Khalil was involved in the conception of the study and, in collaboration with Noura Al-Kaiedi, Hatim Alhani, Esam Azhar, Ibrahim Al Olayan, and Walid Kandeil, supervised the conduct of the surveillance study. Esam Azhar and Moujahed Kao conducted the serotyping analysis, and Leen Jan Van Doorn conducted the genotyping of rotavirus strains. Robert Pawinski, Sameh Anis, and Walid Kandeil were involved in the design. Kusuma Gopala conducted the statistical analysis, and Rodrigo DeAntonio contributed to the analysis and interpretation of the results. All authors contributed toward data analysis, drafting and revising the paper and agree to be accountable for all aspects of the work. 


\section{Disclosure}

Mohamed Khalil declares to have received traveling fee from GlaxoSmithKline Biologicals SA to present the study at European Society for Paediatric Infectious Diseases 2012 Congress. Noura Al-Kaiedi, Hatim Alhani, Ibrahim Al Olayan, Esam Azhar, Moujahed Kao, and Leen Jan Van Doorn have no conflicts of interest to declare. Robert Pawinski and Sameh Anis were employed by GlaxoSmithKline (GSK) group of companies during the conduct of the study. Walid Kandeil, Kusuma Gopala, and Rodrigo DeAntonio are employed by GSK group of companies. Rodrigo DeAntonio and Walid Kandeil have GSK stock options. Rotarix is a trademark of the GSK group of companies. RotaTeq is a trademark of Merck \& Company Inc. IDEIA is a trademark of Ely, UK. The authors report no other conflicts of interest in this work.

\section{References}

1. Buttery JP, Kirkwood C. Rotavirus vaccines in developed countries. Curr Opin Infect Dis. 2007;20:253-258.

2. Parashar UD, Steele D, Neuzil K, et al. Progress with rotavirus vaccines: summary of the Tenth International Rotavirus Symposium. Expert Rev Vaccines. 2013;12(2):113-117.

3. Tate JE, Patel MM, Steele AD, et al. Global impact of rotavirus vaccines. Expert Rev Vaccines. 2010;9:395-407.

4. Kotloff KL, Nataro JP, Blackwelder WC, et al. Burden and aetiology of diarrhoeal disease in infants and young children in developing countries (the Global Enteric Multicenter Study, GEMS): a prospective, casecontrol study. Lancet. 2013;382:209-222.

5. Parashar UD, Burton A, Lanata C, et al. Global mortality associated with rotavirus disease among children in 2004. J Infect Dis. 2009; 200(Suppl 1):S9-S15.

6. WHO. WHO vaccine-preventable diseases: monitoring system. 2013 global summary; 2014 [cited; Last updated June 4, 2013]. Available from: http://apps.who.int/immunization_monitoring/globalsummary/ countries?countrycriteria $\% 5 \mathrm{~B}$ country $\% 5 \mathrm{D} \% 5 \mathrm{~B} \% 5 \mathrm{D}=\mathrm{SAU}$. Accessed February 14, 2014.

7. Aithala G, Al Dhahry SH, Saha A, Elbualy MS. Epidemiological and clinical features of rotavirus gastroenteritis in Oman. $J$ Trop Pediatr. 1996;42:54-57.

8. Dutta SR, Khalfan SA, Baig BH, Philipose L, Fulayfil R. Epidemiology of rotavirus diarrhoea in children under five years in Bahrain. Int $J$ Epidemiol. 1990;19:722-727.

9. Sethi SK, Al-Nakib W, Khuffash FA, Majeed HA. Acute diarrhoea and rotavirus infections in young children in Kuwait. Ann Trop Paediatr. 1984;4:117-121.

10. el Assouli SM, Banjar ZM, Mohammed KA, Zamakhchari FT. Rotavirus infection in children in Saudi Arabia. Am J Trop Med Hyg. 1992;46:272-277.

11. elAssouli SM, Banjar ZM, Mohammed KA, Millat WA, elAssouli MZ. Genetic and antigenic analysis of human rotavirus prevalent in Al-Taif, Saudi Arabia. J Trop Paediatr. 1996;42:211-219.

12. Huq MI, Rahman AS, Al-Sadiq A, Al-Shahri A, Alim AR. Rotavirus as an important cause of diarrhoea in a hospital for children in Dammam, Saudi Arabia. Ann Trop Paediatr. 1987;7:173-176.

13. Mohammed KA, el Assouli SM, Banjar ZM. Human rotavirus subgroups and serotypes in children with acute gastroenteritis in Saudi Arabia from 1988 to 1992. J Med Virol. 1994;44:237-242.

14. el-Sheikh SM, el-Assouli SM. Prevalence of viral, bacterial and parasitic enteropathogens among young children with acute diarrhoea in Jeddah, Saudi Arabia. J Health Popul Nutr. 2001;19:25-30.
15. Milaat WA, Elassouli SM. Epidemiology of diarrhoea in two major cities in Saudi Arabia. J Commun Dis. 1995;27:84-91.

16. Kheyami AM, Cunliffe NA, Hart CA. Rotavirus infection in Saudi Arabia. Ann Saudi Med. 2006;26:184-191.

17. Afifi R, Nabiha M. The burden of Rotavirus gastroenteritis among hospitalized pediatric patients in a tertiary referral hospital in Jeddah. Ann Saudi Med. 2013;33:241-246.

18. Ghazi HO, Khan MA, Telmesani AM, Idress B, Mahomed MF. Rotavirus infection in infants and young children in Makkah, Saudi Arabia. J Pak Med Assoc. 2005;55:231-234.

19. Khoury H, Ogilvie I, El Khoury AC, Duan Y, Goetghebeur MM. Burden of rotavirus gastroenteritis in the Middle Eastern and North African pediatric population. BMC Infect Dis. 2011;11:9.

20. Zlamy M, Kofler S, Orth D, et al. The impact of Rotavirus mass vaccination on hospitalization rates, nosocomial Rotavirus gastroenteritis and secondary blood stream infections. BMC Infect Dis. 2013; $13: 112$

21. Rotavirus vaccines. WHO position paper - January 2013. Wkly Epidemiol Rec. 2013;88:49-64.

22. Soares-Weiser K, Maclehose H, Bergman H, et al. Vaccines for preventing rotavirus diarrhoea: vaccines in use. Cochrane Database Syst Rev. 2012;2:CD008521

23. Lepage $P$, Vergison A. Impact of rotavirus vaccines on rotavirus disease. Expert Rev Anti Infect Ther. 2012;10(5):547-561.

24. World Health Organization. Rotavirus vaccine and intussusception: report from an expert consultation. Wkly Epidemiol Rec. 2011;86: 317-324.

25. Meeting of the Strategic Advisory Group of Experts on immunization, October 2009 - conclusions and recommendations. Wkly Epidemiol Rec. 2009;84:517-532.

26. Cortese MM, Parashar UD. Prevention of rotavirus gastroenteritis among infants and children: recommendations of the Advisory Committee on Immunization Practices (ACIP). MMWR Recomm Rep. 2009;58:1-25.

27. World Health Organization. Generic protocol for i) hospital-based surveillance to estimate the burden of rotavirus among children and ii) a community-based survey on utilization of health care services for gastroenteritis in children: field test version; 2002 [cited 2013]. Available from: http://whqlibdoc.who.int/hq/2002/WHO_V\&B_02.15. pdf. Accessed February 14, 2014.

28. Ruuska T, Vesikari T. Rotavirus disease in Finnish children: use of numerical scores for clinical severity of diarrhoeal episodes. Scand $J$ Infect Dis. 1990;22:259-267.

29. van Doorn LJ, Kleter B, Hoefnagel E, et al. Detection and genotyping of human rotavirus VP4 and VP7 genes by reverse transcriptase PCR and reverse hybridization. J Clin Microbiol. 2009;47:2704-2712.

30. Parashar UD, Hummelman EG, Bresee JS, Miller MA, Glass RI. Global illness and deaths caused by rotavirus disease in children. Emerg Infect Dis. 2003;9:565-572.

31. Malek MA, Teleb N, Abu-Elyazeed R, et al. The epidemiology of rotavirus diarrhea in countries in the Eastern Mediterranean Region. J Infect Dis. 2010;202(Suppl 1):S12-S22.

32. Centers for Disease Control and Prevention. Rotavirus surveillance - worldwide, 2009. MMWR Morb Mortal Wkly Rep. 2011; 60:514-516.

33. Eesteghamati A, Gouya M, Keshtkar A, et al. Sentinel hospitalbased surveillance of rotavirus diarrhea in Iran. J Infect Dis. 2009; 200(Suppl 1):S244-S247.

34. Nafi O. Rotavirus gastroenteritis among children aged under 5 years in Al Karak, Jordan. East Mediterr Health J. 2010;16:1064-1069.

35. Forster J, Guarino A, Parez N, et al; Rotavirus Study Group. Hospital-based surveillance to estimate the burden of rotavirus gastroenteritis among European children younger than 5 years of age. Pediatrics. 2009;123:e393-e400.

36. Arif M, El-Hazmi MM. Viral gastroenteritis in Saudi children. Saudi Med J. 2005;26:1017-1018. 
37. Tayeb HT, Dela Cruz DM, Al-Qahtani A, Al-Ahdal MN, Carter MJ. Enteric viruses in pediatric diarrhea in Saudi Arabia. J Med Virol. 2008;80:1919-1929.

38. Al Awaidy SA, Bawikar S, Al Busaidy S, et al. Considerations for introduction of a rotavirus vaccine in Oman: rotavirus disease and economic burden. J Infect Dis. 2009;200(Suppl 1):S248-S253.

39. Ceyhan M, Alhan E, Salman N, et al. Multicenter prospective study on the burden of rotavirus gastroenteritis in Turkey, 2005-2006: a hospitalbased study. J Infect Dis. 2009;200(Supp1 1):S234-S238.

40. Kheyami AM, Nakagomi T, Nakagomi O, Dove W, Hart CA, Cunliffe NA. Molecular epidemiology of rotavirus diarrhea among children in Saudi Arabia: first detection of G9 and G12 strains. J Clin Microbiol. 2008;46:1185-1191.

41. Musawi MA, Zainaldeen H, Shafi F. Rotavirus gastroenteritis in children under 5 years in the Kingdom of Bahrain: hospital-based surveillance. Clin Epidemiol. 2013;5:269-275.

42. Al Baqlani S, Peenze I, Dewar J, et al. Molecular characterization of rotavirus strains circulating in Oman in 2005. J Infect Dis. 2010 202(Suppl):S258-S262.

43. Wheeler JG, Sethi D, Cowden JM, et al. Study of infectious intestinal disease in England: rates in the community, presenting to general practice, and reported to national surveillance. BMJ. 1999;318:1046-1050.
44. Tam CC, Rodrigues LC, Viviani L, et al; IID2 Study Executive Committee. Longitudinal study of infectious intestinal disease in the UK (IID2 study): incidence in the community and presenting to general practice. Gut. 2012;61:69-77.

45. Mrukowicz J, Szajewska H, Vesikari T. Options for the prevention of rotavirus disease other than vaccination. J Pediatr Gastroenterol Nutr. 2008;46(Suppl 2):S32-S37.

46. Patel MM, Steele D, Gentsch JR, et al. Real-world impact of rotavirus vaccination. Pediatr Infect Dis J. 2011;30(1 Suppl):S1-S5.

47. Paulke-Korinek M, Rendi-Wagner P, Kundi M, Kronik R, Kollaritsch H. Universal mass vaccination against rotavirus gastroenteritis: impact on hospitalization rates in Austrian children. Pediatr Infect Dis J. 2010;29:319-323.

48. Richardson V, Hernandez-Pichardo J, Quintanar-Solares M, et al. Effect of rotavirus vaccination on death from childhood diarrhea in Mexico. N Engl J Med. 2010;362:299-305.

49. PATH. Country National Immunization Program (NIP) Introduction of Rotavirus Vaccine; [cited February 19, 2013]. Available from: http://sites. path.org/rotavirusvaccine/files/2014/11/PATH-Country-IntroductionTable_11.27.pdf. Accessed December 8, 2014.

50. Almalki M, Fitzgerald G, Clark M. Health care system in Saudi Arabia: an overview. East Mediterr Health J. 2011;17:784-793.
Clinical Epidemiology

\section{Publish your work in this journal}

Clinical Epidemiology is an international, peer-reviewed, open access, online journal focusing on disease and drug epidemiology, identification of risk factors and screening procedures to develop optimal preventative initiatives and programs. Specific topics include: diagnosis, prognosis, treatment, screening, prevention, risk factor modification,

Submit your manuscript here: http://www.dovepress.com/clinical-epidemiology-journa

\section{Dovepress}

systematic reviews, risk \& safety of medical interventions, epidemiology \& biostatistical methods, and evaluation of guidelines, translational medicine, health policies \& economic evaluations. The manuscript management system is completely online and includes a very quick and fair peer-review system, which is all easy to use. 